\title{
Ginseng extract and ginsenoside Rb1 attenuate carbon tetrachloride-induced liver fibrosis in rats
}

\author{
Ya-Ling Hou', Ya-Hui Tsai', Yun-Ho Lin² and Jane C-J Chao ${ }^{1,3,4^{*}}$
}

\begin{abstract}
Background: Ginsenosides, the major bioactive compounds in ginseng root, have been found to have antioxidant, immunomodulatory and anti-inflammatory activities. This study investigated the effects of ginsenosides on carbon tetrachloride $\left(\mathrm{CCl}_{4}\right)$-induced hepatitis and liver fibrosis in rats.

Methods: Male Sprague-Dawley rats were randomly divided into four groups: control, $\mathrm{CCl}_{4}, \mathrm{CCl}_{4}+0.5 \mathrm{~g} / \mathrm{kg}$ Panax ginseng extract and $\mathrm{CCl}_{4}+0.05 \mathrm{~g} / \mathrm{kg}$ ginsenoside $\mathrm{Rb} 1$ groups. The treated groups were orally given Panax ginseng extract or ginsenoside Rb1 two weeks before the induction of liver injury for successive 9 weeks. Liver injury was induced by intraperitoneally injected with $400 \mathrm{ml} / / \mathrm{CCl}_{4}$ at a dose of $0.75 \mathrm{ml} / \mathrm{kg}$ body weight weekly for 7 weeks. The control group was intraperitoneally injected with olive oil.

Results: The pathological results showed that ginsenoside Rb1 decreased hepatic fat deposition ( $2.65 \pm 0.82$ vs 3.50 $\pm 0.75, p<0.05)$ and Panax ginseng extract lowered hepatic reticular fiber accumulation $(1.05 \pm 0.44$ vs $1.60 \pm 0.39, p$ $<0.01)$ increased by $\mathrm{CCl}_{4}$. Plasma alanine aminotransferase and aspartate aminotransferase activities were increased by $\mathrm{CCl}_{4}(p<0.01)$, and aspartate aminotransferase activity was decreased by Panax ginseng extract at week $9(p<0.05)$. Exposure to $\mathrm{CCl}_{4}$ for 7 weeks, the levels of plasma and hepatic triglycerides $(p<0.01)$, hepatic cholesterol $(p<0.01)$, interleukin-1 $\beta(p<0.01)$, prostaglandin $\mathrm{E}_{2}(p<0.05)$, soluble intercellular adhesion molecule-1 $(p<0.05)$, hydroxyproline $(p<0.05)$, matrix metalloproteinase-2 $(p<0.05)$ and tissue inhibitor of metalloproteinase-1 (TIMP-1) $(p<0.01)$ were elevated, however, hepatic interleukin-10 level was lowered $(p<0.05)$. Both Panax ginseng extract and ginsenoside Rb1 decreased plasma and hepatic triglyceride, hepatic prostaglandin $E_{2}$, hydroxyproline and TIMP-1 levels, and Panax ginseng extract further inhibited interleukin-1 $\beta$ concentrations $(p<0.05)$.
\end{abstract}

Conclusions: Panax ginseng extract and ginsenoside Rb1 attenuate plasma aminotransferase activities and liver inflammation to inhibit $\mathrm{CCl}_{4}$-induced liver fibrosis through down-regulation of hepatic prostaglandin $\mathrm{E}_{2}$ and TIMP-1.

Keywords: Ginsenoside Rb1, Carbon tetrachloride, Interleukin-1 $\beta$, Liver fibrosis, Tissue inhibitor of metalloproteinase-1

\section{Background}

Liver cirrhosis is an irreversible stage in the process of liver damage that occurs after liver fibrosis. Liver fibrosis is attributed to inflammation, excessive accumulation of extracellular matrix and tissue remodeling under wound healing [1]. Chronic hepatitis and liver cirrhosis are positively associated with the occurrence of hepatocellular carcinoma [2,3]. Therefore, the inhibition of hepatic

\footnotetext{
* Correspondence: chenjui@tmu.edu.tw

'School of Nutrition and Health Sciences, College of Public Health and Nutrition, Taipei Medical University, Taipei 110, Taiwan

${ }^{3}$ Master Program in Global Health and Development, College of Public

Health and Nutrition, Taipei Medical University, Taipei 110, Taiwan

Full list of author information is available at the end of the article
}

inflammation and fibrosis is crucial in preventing the occurrence of liver cirrhosis and hepatocellular carcinoma.

Oxidative stress from reactive oxygen species plays an important role in liver fibrogenesis [4]. Carbon tetrachloride $\left(\mathrm{CCl}_{4}\right)$ is considered as a toxic chemical that induces hepatotoxicity including fatty degeneration, inflammation, fibrosis, hepatocellular death and carcinogenicity $[5,6]$. Trichloromethyl radical produced from the metabolism of $\mathrm{CCl}_{4}$ initiates a chain reaction to cause lipid peroxidation, membrane dysfunction and further hepatotoxic damage [6]. The toxic metabolite of $\mathrm{CCl}_{4}$ can activate Kupffer cells to secrete cytokines such as interleukin-1 (IL-1) and tumor necrosis factor- $\alpha$ (TNF- $\alpha)$, stimulate transforming growth factor- $\beta$ (TGF- $\beta$ ) production, inhibit 
nitric oxide (NO) formation and induce inflammation and liver fibrosis [6-8]. Matrix metalloproteinase (MMP)-2, known as type IV collagenase and gelatinase $\mathrm{A}$, acts as the regulator for the breakdown of extracellular matrix, and tissue inhibitor metalloproteinase (TIMP)-1, as the inhibitor of MMPs, exhibits anti-fibrolytic, growth-stimulated and anti-apoptotic activities [9]. Chronic exposure of $\mathrm{CCl}_{4}$ leads to liver fibrosis, which diminishes extracellular matrix degradation and increases MMP-2 secretion through the induction of tissue inhibitor TIMPs [9].

Panax ginseng ( $P$. ginseng) root has been commonly used in oriental medicine, diet or dietary supplement. Ginsenosides, a class of steroid glycosides and triterpene saponins, are the major bioactive compounds in $P$. ginseng root and ginsenoside $\mathrm{Rb} 1\left(\mathrm{C}_{54} \mathrm{H}_{92} \mathrm{O}_{23}\right.$, molecular weight: 1109.3) is considered as the most abundant ginsenoside among more than 30 ginsenosides in $P$. ginseng $[10,11]$. The previous studies have reported that $P$. ginseng and its active components or metabolites had antioxidant, immunomodulatory, anti-inflammatory, and lipid-lowering effects [12-15]. Many studies have shown that ginsenoside $\mathrm{Rb} 1$ and its metabolite compound $\mathrm{K}$ attenuated liver injury through inhibiting lipid peroxidation, TNF- $\alpha$, $\mathrm{NO}$, prostaglandin $\mathrm{E}_{2}\left(\mathrm{PGE}_{2}\right)$, intercellular adhesion molecule (ICAM)-1 and nuclear factor $-\kappa B(N F-\kappa B)$ activation [16-19]. However, the effect of ginsenosides on liver fibrosis is not clear. Considering ginsenoside Rb1 as the most abundant ginsenoside in P. ginseng $[10,11]$ and its hepatoprotective activity [16-19], therefore, this study investigated the protective effects of $P$. ginseng extract (ginseng extract) and ginsenoside $\mathrm{Rb} 1$ on $\mathrm{CCl}_{4}$ induced liver inflammation and fibrosis in rats.

\section{Methods}

\section{Animals and treatments}

Sprague-Dawley rats weighing 200-250 g were purchased from the National Laboratory Animal Center (Taipei, Taiwan). Rats were housed under a 12-h light-dark cycle at $22-24^{\circ} \mathrm{C}$ with a relative humidity of $65-70 \%$. After one-week adaptation, rats were randomly divided into four groups ( $n=10$ per group): control, $\mathrm{CCl}_{4}, \mathrm{CCl}_{4}+$ ginseng extract (GE) and $\mathrm{CCl}_{4}+$ ginsenoside $\mathrm{Rb} 1$ (Rb1) groups. The normal diet based on Laboratory Rodent Diet 5001 powder was purchased from PMI Nutrition International Inc. (Brentwood, MO). Ginseng extract (Ashland Inc., Covington, KY, USA) containing $800 \mathrm{~g}$ ginsenosides/kg extract (80\%) (ginsenosides in the extract include Rb1, Rc, Rd, Rg1, Rg2, Rg3, Rh1 and Rh2) and ginsenoside Rb1 (China Chemical \& Pharmaceutical Co., Ltd., Taipei, Taiwan) with $98 \%$ purity were blended with the normal diet at a dose of $0.5 \mathrm{~g} / \mathrm{kg}$ and $0.05 \mathrm{~g} / \mathrm{kg}$, respectively. Ginsenoside Rb1 content was equal in the GE and Rb1 groups. Rats were fed ginseng extract or ginsenoside Rb1 two weeks before (week 0, W0) the induction of liver injury by intraperitoneal injection of $400 \mathrm{ml} / \mathrm{l} \mathrm{CCl}_{4}$ in olive oil at a dose of $0.75 \mathrm{ml} / \mathrm{kg}$ body weight weekly for 7 weeks. The control group was injected with an equal volume of olive oil without $\mathrm{CCl}_{4}$. Food intake, water intake and body weight were recorded throughout 9-week experimental period. This study was approved by the Institutional Animal Care and Use Committee of Taipei Medical University.

\section{Histopathological examination}

After 9 weeks, rats were euthanized with ether and liver samples from left lateral lobe, median lobe and right lateral lobe were collected for histopathological and biochemical analyses. Excised liver specimens from different lobes $(1 \mathrm{~cm} \times 1 \mathrm{~cm})$ were fixed in $10 \%$ paraformaldehyde, embedded in paraffin, sectioned and stained with hematoxylin and eosin (H\&E), Masson's trichrome or silver. The specimens were coded with a single-blind method and graded from 0 (no lesion), 1 (trace lesion), 2 (weak lesion), 3 (moderate lesion) to 4 (severe lesion) for fat changes, and from 0 (no lesion), 1 (lesion in the central vein area), 2 (lesion in the central vein area and expansion to the surrounding area) to 3 (lesion in the central and portal vein areas or cirrhosis) for necrosis, inflammation, and fibrosis under a light microscope by a pathologist.

\section{Plasma alanine aminotransferase (ALT) and aspartate aminotransferase (AST) activities}

Blood samples from rat tails were collected into heparincontaining tubes at weeks $0,2\left(\mathrm{CCl}_{4}\right.$ injection) and 9 . Blood was centrifuged at $3000 \mathrm{~g}$ for $15 \mathrm{~min}$ at $4^{\circ} \mathrm{C}$. Plasma ALT and AST activities were measured spectrophotometrically at $570 \mathrm{~nm}$ using a commercial kit (RM 163-K, Iatron Laboratories Inc., Tokyo, Japan).

\section{Plasma and hepatic lipid concentrations}

Blood samples from rat tails were collected at weeks 0, 2 and 9 , and centrifuged at $3000 \mathrm{~g}$ for $15 \mathrm{~min}$ at $4^{\circ} \mathrm{C}$. Liver samples from left lateral lobe, median lobe and right lateral lobe were homogenized in chloroform/methanol (2:1) solution and extracted by chloroform/methanol/ water (3:48:47) solution. Triglycerides and total cholesterol concentrations in plasma and liver were determined spectrophotometrically at $500 \mathrm{~nm}$ using commercial enzymatic kits (Randox ${ }^{\ominus}$ TR213 for triglycerides, Randox ${ }^{\odot}$ CH201 for total cholesterol, Randox Laboratories Ltd., London, UK).

\section{Hepatic inflammatory markers}

Liver slices $(0.5 \mathrm{~g})$ were homogenized in $1.5 \mathrm{~mL}$ of buffer solution $(50 \mathrm{mmol} / \mathrm{l}$ Tris, $150 \mathrm{mmol} / \mathrm{l} \mathrm{NaCl}$, and $10 \mathrm{ml} / \mathrm{l}$ Triton X-100, pH 7.2) [20] and mixed with $100 \mu \mathrm{l}$ of proteinase inhibitor cocktail solution (P8340, Sigma-Aldrich, 
Inc., Saint Louis, USA). Liver homogenate was centrifuged at $3000 \mathrm{~g}$ for $15 \mathrm{~min}$ at $4^{\circ} \mathrm{C}$ for TNF- $\alpha$, IL- $1 \beta$ and IL-10 analysis. For PGE 2 and soluble ICAM-1 (sICAM-1) analysis, liver slices $(0.5 \mathrm{~g})$ were mixed with $1.0 \mathrm{ml}$ of homogenized buffer $(0.25 \mathrm{~mol} / \mathrm{l}$ sucrose, $50 \mathrm{mmol} / \mathrm{l}$ Tris $-\mathrm{HCl}$, and $5 \mathrm{mmol} / \mathrm{l}$ EDTA, pH 7.5). Liver homogenate was centrifuged at $8000 \mathrm{~g}$ for $15 \mathrm{~min}$ at $4^{\circ} \mathrm{C}$.

Hepatic TNF- $\alpha$, IL-1 $\beta$, IL-10, PGE 2 and sICAM-1 levels were measured spectrophotometrically using enzymelinked immunosorbent assay (ELISA) kits (Quantikine RTA00 for TNF- $\alpha$, Quantikine ${ }^{\varpi}$ RLB00 for IL-1 $\beta$, DuoSet ${ }^{\circ}$ DY522 for IL-10, PGE 2 , Quantikine ${ }^{\bullet}$ KE004 for $\mathrm{PGE}_{2}$, Quantikine $^{\curvearrowleft}$ RIC100 for sICAM-1, R\&D Systems, Inc., Minneapolis, USA). Hepatic supernatant was separately incubated with rat anti-TNF- $\alpha$, anti-IL-1 $\beta$, anti-IL-10, anti-PGE ${ }_{2}$ or anti-sICAM-1, then washed with wash buffer $\left(0.05 \%\right.$ Tween $^{\circ}$ in phosphate buffer solution, PBS) followed by incubation with polyclonal antibody against TNF- $\alpha$, IL-1 $\beta$, PGE $_{2}$ or sICAM-1 conjugated to horseradish peroxidase or biotinylated anti-IL-10 secondary antibody with streptavidin conjugated to horseradish peroxidase, respectively. After washed with wash buffer several times, the substrate solution (hydrogen peroxide and chromogen tetramethylbenzidine) was added and the reaction was terminated by adding diluted hydrochloric acid. The absorbance was determined at $450 \mathrm{~nm}$. Protein concentration was measured by the method of Lowry et al. [21].

\section{Hepatic hydroxyproline, MMP-2 and TIMP-1 levels}

Hepatic hydroxyproline level was measured by colorimetric assay. Freeze-dried liver specimen $(0.25 \mathrm{~g})$ was homogenized with $2 \mathrm{ml}$ of distilled water. Liver homogenate was hydrolyzed in alkaline solution $(2 \mathrm{~mol} / \mathrm{L} \mathrm{NaOH})$, oxidized with chloramines $\mathrm{T}$ reagent, and incubated with Ehrlich's reagent at $65^{\circ} \mathrm{C}$. The chromogenic product was determined spectrophotometrically at $550 \mathrm{~nm}$.

The levels of MMP-2 and TIMP-1 in the liver were determined by commercial kits (Quantikine DMP200 for MMP-2, Quantikine RTM100 TIMP-1, R\&D Systems, Inc.) using ELISA. Liver slices were homogenized with PBS and proteinase inhibitor cocktail solution and centrifuged at $12000 \mathrm{~g}$ for $10 \mathrm{~min}$ at $4^{\circ} \mathrm{C}$. The supernatant was centrifuged again and collected for further analysis. Hepatic supernatant was separately incubated with rat anti-MMP-2 or anti- TIMP-1, washed with wash buffer, and incubated with polyclonal antibody against MMP-2 or TIMP-1 conjugated to horseradish peroxidase followed by several washes with wash buffer. The substrate solution (hydrogen peroxide and chromogen tetramethylbenzidine) was added for the reaction and stop solution (diluted hydrochloric acid) was then added to stop the reaction. The absorbance was measured at $450 \mathrm{~nm}$.

\section{Statistical analysis}

All data were expressed as mean \pm SD. The data were analyzed by one-way analysis of variance (ANOVA) using Statistical Analysis System (SAS version 9.1, SAS Institute Inc., Cary, NC, USA). The difference between any two groups was analyzed by Fisher's least significant difference test. A value $p<0.05$ was considered significant.

\section{Results}

\section{Body weight, liver weight and food intake}

The results of body weight, liver weight and food intake were shown in Table 1 to monitor the effects of the treatments on gross growth and liver weight. Final body weight and weight gain were significantly higher in the control group than those in the $\mathrm{CCl}_{4}(p<0.01)$, GE $(p<0.05)$, and $\operatorname{Rb} 1(p<0.05)$ groups (Table 1$)$, but not significantly different among the three $\mathrm{CCl}_{4}$ treated groups. Daily intake of ginseng extract and ginsenoside $\mathrm{Rb} 1$ was $12.6 \pm 0.6 \mathrm{mg}(33.8 \pm 1.5 \mathrm{mg} / \mathrm{kg}$ body weight $)$ and $1.3 \pm 0.6 \mathrm{mg}(3.3 \pm 0.1 \mathrm{mg} / \mathrm{kg}$ body weight $)$ in the GE and $\mathrm{Rb} 1$ groups, respectively. The relative liver weight was significantly higher in the $\mathrm{CCl}_{4}$ and $\mathrm{GE}$ groups than that in the control group $(p<0.01)$. The $\mathrm{Rb} 1$ group significantly reduced the relative liver weight compared with the $\mathrm{CCl}_{4}$ group $(p<0.05)$. However, total liver weight and daily food intake did not differ significantly among the four groups.

\section{Histopathological examination}

The results of the histopathological examination by different stains were demonstrated in Figures 1 and 2 to determine the effects of the treatments on histopathological changes in the liver, especially on liver fibrosis. The bright red color of H\&E staining shown in Figure 1A could be resulted from strong eosin staining, a fluorescent red dye. The pathological sections stained by $H \& E$ showed that no fat was accumulated in the liver of the control group, whereas large fat vacuoles were observed in the liver of the $\mathrm{CCl}_{4}$ group (Figure 1A). However, the $\mathrm{Rb} 1$ group had significantly decreased fat vacuoles

\begin{tabular}{|c|c|c|c|c|}
\hline & Control & $\mathrm{CCl}_{4}$ & GE & $\mathrm{Rb} 1$ \\
\hline Initial body weight (g) & $240 \pm 8^{a}$ & $233 \pm 12^{a}$ & $236 \pm 14^{a}$ & $239 \pm 15^{a}$ \\
\hline Final body weight (g) & $478 \pm 23^{b}$ & $427 \pm 25^{\mathrm{a}}$ & $433 \pm 38^{\mathrm{a}}$ & $448 \pm 37^{a}$ \\
\hline Weight gain (g) & $238 \pm 22^{b}$ & $194 \pm 23^{\mathrm{a}}$ & $208 \pm 34^{\mathrm{a}}$ & $209 \pm 30^{a}$ \\
\hline Total liver weight (g) & $15.9 \pm 2.5^{\mathrm{a}}$ & $17.5 \pm 1.5^{\mathrm{a}}$ & $17.3 \pm 3.8^{\mathrm{a}}$ & $16.4 \pm 1.8^{\mathrm{a}}$ \\
\hline $\begin{array}{l}\text { Relative liver } \\
\text { weight }(\mathrm{g} / \mathrm{kg})\end{array}$ & $33.2 \pm 4.8^{\mathrm{a}}$ & $41.1 \pm 3.4^{c}$ & $39.7 \pm 5.8^{b c}$ & $36.7 \pm 3.4^{\mathrm{ab}}$ \\
\hline Food intake $(\mathrm{g} / \mathrm{d})$ & $26.5 \pm 1.6^{\mathrm{a}}$ & $25.3 \pm 1.0^{a}$ & $25.2 \pm 1.2^{\mathrm{a}}$ & $25.4 \pm 1.2^{\mathrm{a}}$ \\
\hline
\end{tabular}

Data are presented as mean $\pm S D(n=10)$. Values not sharing the same superscript differ significantly $(p<0.05)$ within the same row. 

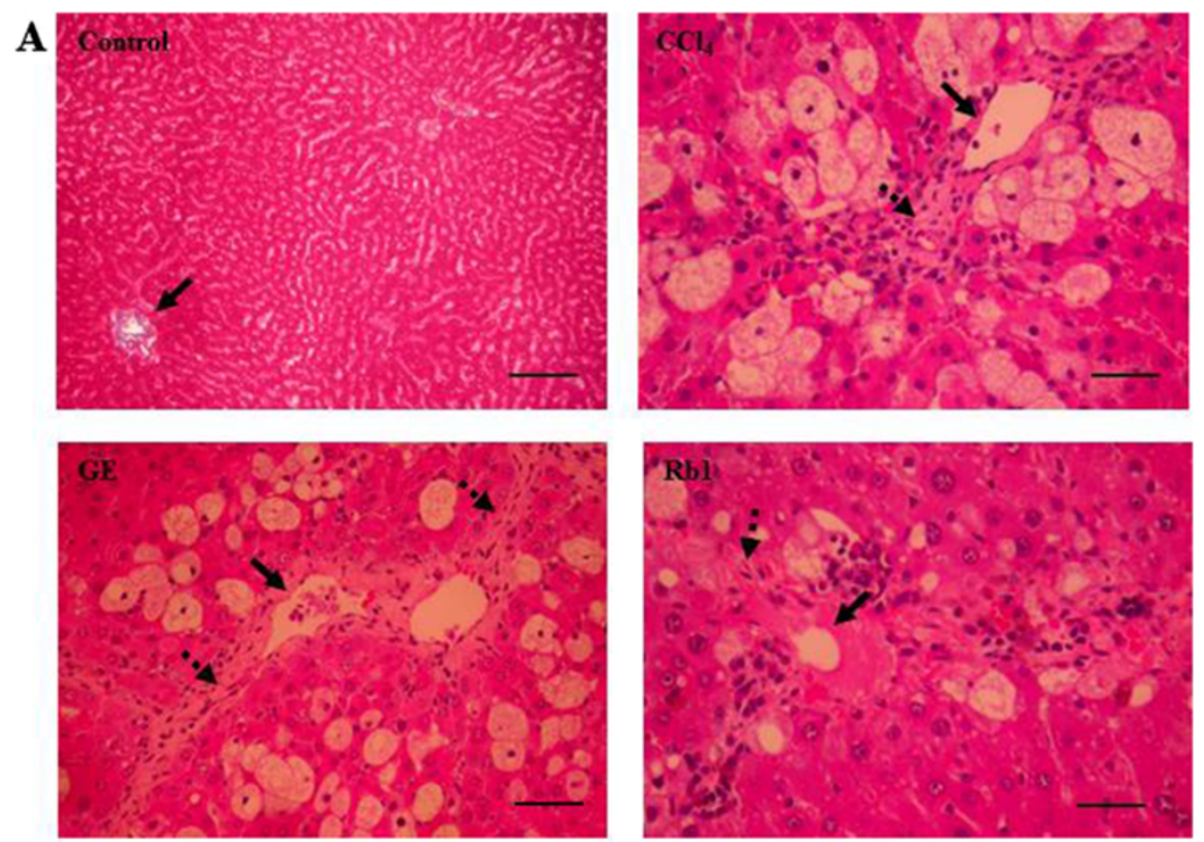

B

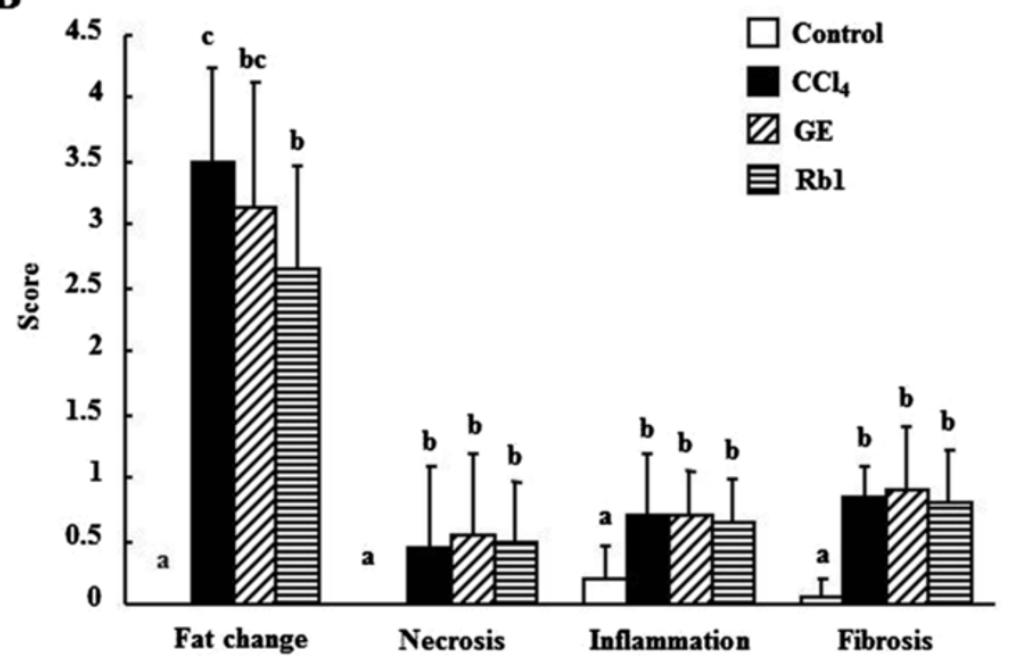

Figure 1 The representative histological sections of rat liver specimens. A: hematoxylin and eosin stain at $20 \times 10$ magnification, B: semi-quantitative scores graded from 0 (no lesion), 1 (trace lesion), 2 (weak lesion), 3 (moderate lesion) to 4 (severe lesion) for fat changes, and from 0 (no lesion), 1 (lesion in the central vein area), 2 (lesion in the central vein area and expansion to the surrounding area) to 3 (lesion in the central and portal vein areas or cirrhosis) for necrosis, inflammation and fibrosis in control, $\mathrm{CCl}_{4}, \mathrm{GE}$ and $\mathrm{Rb} 1$ groups. Solid and dashed arrows represent the central vein and collagen fibers. Data are presented as mean $\pm S D(n=10)$. Values not sharing the same letter differ significantly $(p<0.05)$. Scale bar $=50 \mu m$.

compared with the $\mathrm{CCl}_{4}$ group $(2.65 \pm 0.82$ vs. $3.50 \pm 0.75$, $p<0.05)$ (Figure 1B). The pathological scores for fat change were not significantly different between the GE and Rb1 groups. The $\mathrm{CCl}_{4}, \mathrm{GE}$, and $\mathrm{Rb} 1$ groups had significantly elevated cell necrosis $(p<0.05)$, inflammatory cells $(p<0.01)$, and fibrosis $(p<0.01)$ in the central veins compared with the control group. However, the pathological scores for necrosis, inflammation, and fibrosis in the liver did not significantly differ among the three $\mathrm{CCl}_{4}$ treated groups.
The pathological assessment of liver fibrosis as observed by Masson's trichrome stain demonstrated that the formation of collagen fibers appeared blue was elevated by the exposure to $\mathrm{CCl}_{4}$ (Figure 2A). The fibrosis scores determined by Masson's trichrome stain in the $\mathrm{CCl}_{4}(1.35 \pm 0.34), \mathrm{GE}(1.10 \pm 0.39)$ and $\mathrm{Rb} 1(1.40 \pm 0.39)$ groups were significantly higher compared with the control group $(p<0.01)$ (Figure 2C), but the GE group had a lower liver fibrosis score compared with the $\mathrm{Rb} 1$ group 

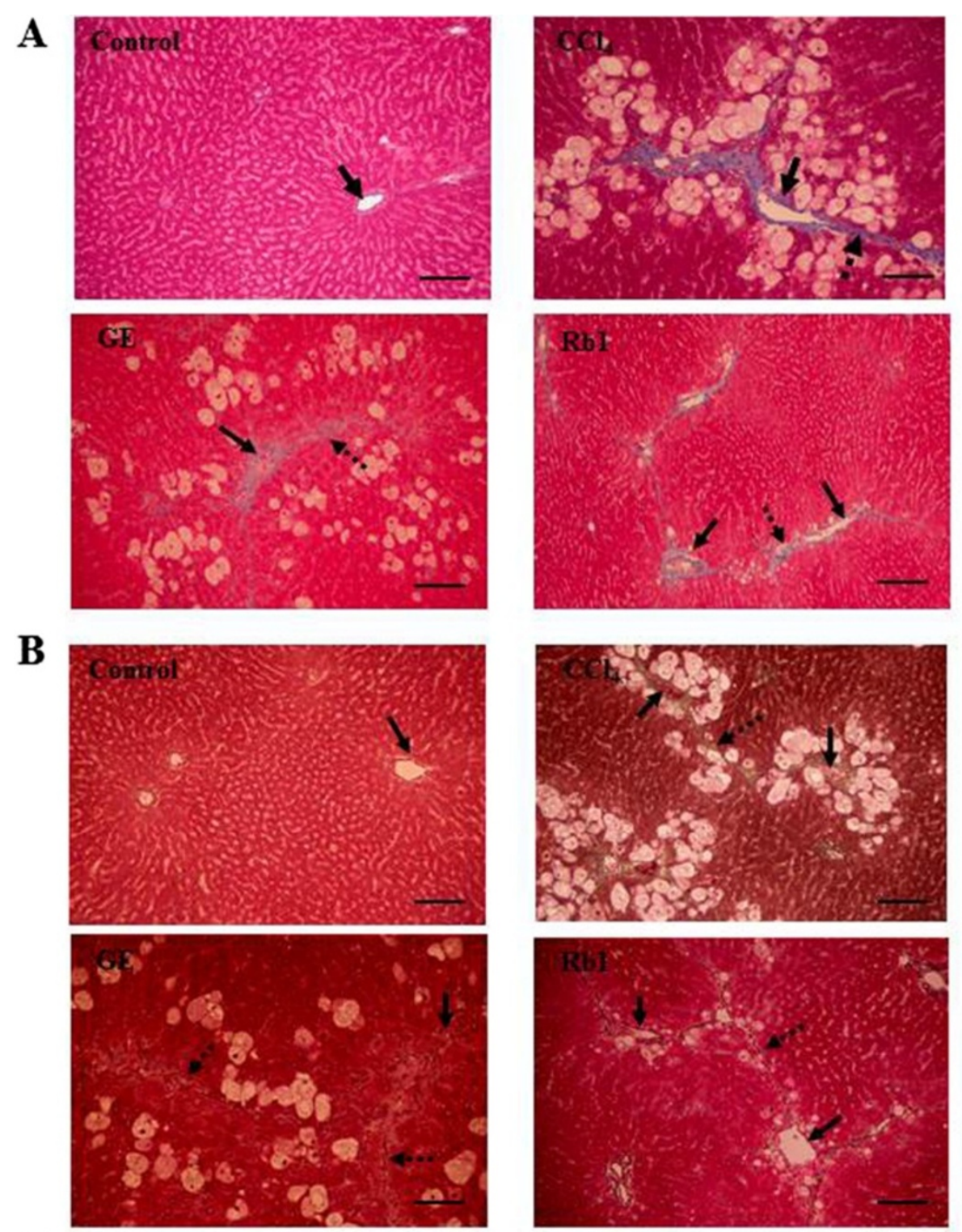

C

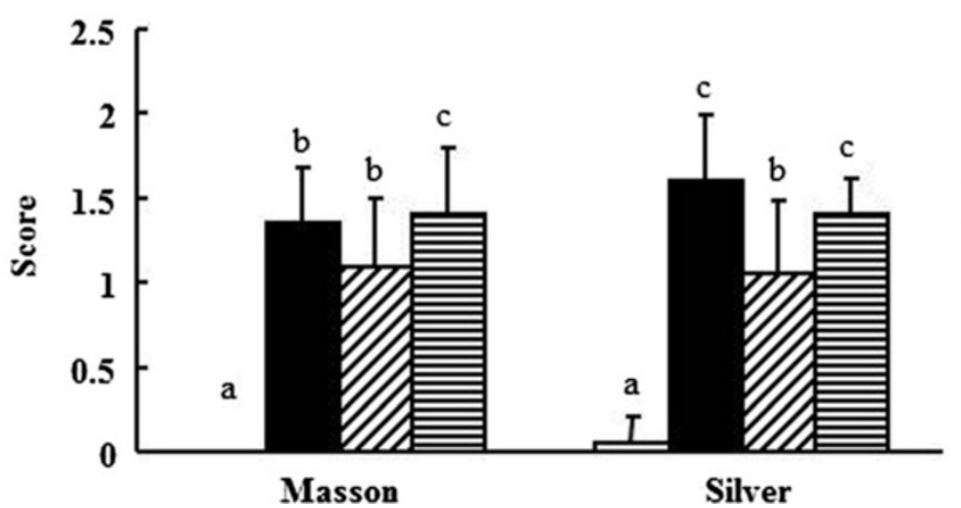

$\square$ Control $-\mathrm{CCl}_{4}$ $\square$ GE 日Rbl

Figure 2 (See legend on next page.) 
(See figure on previous page.)

Figure $\mathbf{2}$ The representative histological sections of rat liver specimens. A: Masson's trichrome stain at $15 \times 10$ magnification, B: silver stain at $15 \times 10$ magnification; $\mathbf{C}$ : semi-quantitative scores graded from 0 (no collagen formation), 1 (collagen formation in the central vein area), 2 (collagen and fibrous bridge formation in different central vein areas) to 3 (cirrhosis) for fibrosis in the control, CCl, $\mathrm{GE}^{2}$ and Rb1 groups. Collagen fibers stained with Masson's trichrome appear blue. Reticular fibers stained with silver appear brown. Solid and dashed arrows represent the central vein and fiber bridging. Data are presented as mean \pm SD $(n=10)$. Values not sharing the same letter differ significantly $(p<0.05)$. Scale bar $=50 \mu m$.

$(p<0.05)$. The accumulation of liver reticular fibers stained by silver and appeared brown was increased by the exposure to $\mathrm{CCl}_{4}(p<0.01)$ (Figure $\left.2 \mathrm{~B}\right)$. The $\mathrm{GE}$ $(1.05 \pm 0.44)$ group had significantly reduced accumulation of reticular fibers than the $\mathrm{CCl}_{4}(1.60 \pm 0.39, p<0.01)$ and $\mathrm{Rb} 1(1.40 \pm 0.21, p<0.05)$ groups (Figure $2 \mathrm{C}$ ).

\section{Plasma ALT and AST activities}

Plasma ALT and AST activities were measured to assess the effects of the treatments on liver functions. Plasma ALT and AST activities were significantly elevated in the $\mathrm{CCl}_{4}$ group than those in the control, GE and $\mathrm{Rb} 1$ groups $(p<0.01)$ after the induction of liver injury (W2) (Table 2). The $\mathrm{CCl}_{4}$ group still had increased plasma ALT $(p<0.05)$ and AST $(p<0.01)$ activities compared with the control group, whereas plasma ALT and AST activities did not differ among the control, GE and Rb1 groups at week 9. The GE group significantly decreased plasma AST activity compared with the $\mathrm{CCl}_{4}$ group at week 9 $(p<0.05)$.

\section{Plasma and hepatic triglyceride and total cholesterol concentrations}

Plasma and hepatic lipid concentrations were determined to evaluate the effects of the treatments on lipid profiles. After the induction of liver injury (W2), plasma triglycerides were significantly increased and still maintained higher level at week 9 in the $\mathrm{CCl}_{4}$ group compared with those in the control group $(p<0.01)$ (Table 3). Treatment with GE $(p<0.01)$ and Rb1 $(p<0.05)$ significantly reduced plasma triglycerides compared with the $\mathrm{CCl}_{4}$ group to the similar level of the control group at weeks 2 and 9.
At the baseline, plasma total cholesterol level was significantly lower in the $\mathrm{CCl}_{4}$ and $\mathrm{Rb} 1$ groups than that in the control group $(p<0.01)$. After the induction of liver injury, total cholesterol level was significantly elevated in the $\mathrm{CCl}_{4}$ group than that in the control and $\mathrm{Rb} 1$ groups $(p<0.05)$ (Table 3). Plasma total cholesterol level did not differ significantly among the four groups at week 9 .

Hepatic triglyceride concentrations were significantly increased by $73 \%$ in the $\mathrm{CCl}_{4}$ group than those in the control group $(p<0.01)$, and decreased by $56 \%$ and $60 \%$ in the GE and Rb1 groups, respectively, compared with the $\mathrm{CCl}_{4}$ group $(p<0.01)$ (Figure 3A). Hepatic total cholesterol level was significantly greater in the $\mathrm{CCl}_{4}, \mathrm{GE}$ and $\mathrm{Rb} 1$ groups than that in the control group $(p<0.01)$, but not significantly different among $\mathrm{CCl}_{4}$ treated groups (Figure 3B).

\section{Hepatic TNF- $\alpha$, IL-1 $\beta$, IL-10, PGE 2 , and sICAM-1 levels}

The results of hepatic cytokine levels were found in Table 4 to determine the effects of the treatments on hepatic mediators released in the inflammatory condition. Hepatic IL-1 $\beta(p<0.01)$, PGE $_{2}(p<0.05)$ and sICAM-1 $(p<0.05)$ levels were significantly elevated, whereas hepatic IL-10 level was significantly decreased in the $\mathrm{CCl}_{4}$ group compared with those in the control group (Table 4). Hepatic TNF- $\alpha$, IL- $1 \beta$ and $\mathrm{PGE}_{2}$ levels were significantly reduced in the GE group compared with the $\mathrm{CCl}_{4}$ group $(p<0.05)$. The $\mathrm{Rb} 1$ group had higher hepatic TNF- $\alpha$ level than the GE group, but lower hepatic $\mathrm{PGE}_{2}$ level than the $\mathrm{CCl}_{4}$ group $(p<0.05)$.

\section{Hepatic hydroxyproline, MMP-2 and TIMP-1 levels}

The results of hepatic hydroxyproline, MMP-2 and TIMP-1 levels were shown in Figure 4 to investigate the

Table 2 Plasma ALT and AST activities in rats treated with ginsenosides

\begin{tabular}{|c|c|c|c|c|}
\hline & Control & $\mathrm{CCl}_{4}$ & GE & Rb1 \\
\hline \multicolumn{5}{|c|}{ ALT activity (IU/I) } \\
\hline wo & $29.6 \pm 2.9^{\mathrm{a}}$ & $27.6 \pm 1.7^{\mathrm{a}}$ & $31.2 \pm 3.8^{\mathrm{a}}$ & $29.2 \pm 32.8^{\mathrm{a}}$ \\
\hline W2 & $33.2 \pm 3.6^{\mathrm{a}}$ & $4012.4 \pm 2212.9^{b}$ & $469.0 \pm 435.2^{\mathrm{a}}$ & $1072.6 \pm 618.6^{a}$ \\
\hline W9 & $33.6 \pm 4.9^{a}$ & $334.9 \pm 379.1^{b}$ & $136.4 \pm 167.4^{\mathrm{ab}}$ & $177.5 \pm 333.0^{\mathrm{ab}}$ \\
\hline \multicolumn{5}{|c|}{ AST activity (IU/I) } \\
\hline wo & $75.9 \pm 6.3^{\mathrm{a}}$ & $78.3 \pm 4.4^{a}$ & $70.8 \pm 23.5^{\mathrm{a}}$ & $77.6 \pm 5.3^{\mathrm{a}}$ \\
\hline W2 & $62.1 \pm 20.2^{a}$ & $8370.4 \pm 5360.8^{b}$ & $2155.0 \pm 1973.8^{a}$ & $1233.6 \pm 616.7^{a}$ \\
\hline W9 & $63.3 \pm 6.0^{\mathrm{a}}$ & $288.4 \pm 181.3^{b}$ & $134.9 \pm 114.6^{\mathrm{a}}$ & $171.3 \pm 227.9^{\mathrm{a}}$ \\
\hline
\end{tabular}

Data are presented as mean \pm SD $(n=10)$. Values not sharing the same superscript differ significantly $(p<0.05)$ within the same row. 
Table 3 Plasma triglycerides and total cholesterol concentrations in rats treated with ginsenosides

\begin{tabular}{lllll}
\hline & Control & $\mathbf{C C l}_{4}$ & GE & Rb1 \\
\hline $\begin{array}{llll}\text { Triglycerides } \\
\text { (mmol/l) }\end{array}$ & & & & \\
W0 & $0.16 \pm 0.04^{\mathrm{a}}$ & $0.16 \pm 0.04^{\mathrm{a}}$ & $0.14 \pm 0.03^{\mathrm{a}}$ & $0.15 \pm 0.02^{\mathrm{a}}$ \\
W2 & $0.24 \pm 0.04^{\mathrm{a}}$ & $0.39 \pm 0.19^{\mathrm{b}}$ & $0.25 \pm 0.04^{\mathrm{a}}$ & $0.28 \pm 0.10^{\mathrm{a}}$ \\
W9 & $0.54 \pm 0.10^{\mathrm{c}}$ & $0.35 \pm 0.06^{\mathrm{b}}$ & $0.27 \pm 0.05^{\mathrm{a}}$ & $0.29 \pm 0.07^{\mathrm{a}}$ \\
Total cholesterol & & & & \\
(mmol/l) & & & & \\
W0 & $0.90 \pm 0.11^{\mathrm{b}}$ & $0.71 \pm 0.12^{\mathrm{a}}$ & $0.79 \pm 0.16^{\mathrm{ab}}$ & $0.75 \pm 0.10^{\mathrm{a}}$ \\
W2 & $1.01 \pm 0.14^{\mathrm{a}}$ & $1.20 \pm 0.18^{\mathrm{b}}$ & $1.05 \pm 0.21^{\mathrm{ab}}$ & $0.95 \pm 0.27^{\mathrm{a}}$ \\
W9 & $0.79 \pm 0.11^{\mathrm{a}}$ & $0.70 \pm 0.17^{\mathrm{a}}$ & $0.67 \pm 0.10^{\mathrm{a}}$ & $0.66 \pm 0.20^{\mathrm{a}}$ \\
\hline
\end{tabular}

Data are presented as mean $\pm S D(n=10)$. Values not sharing the same superscript differ significantly $(p<0.05)$ within the same row. effects of the treatments on liver fibrogenesis and fibrolysis. Hepatic hydroxyproline $(p<0.05)$, MMP-2 $(p<0.05)$ and TIMP-1 $(p<0.01)$ levels were elevated by $55 \%, 28 \%$ and $61 \%$, respectively, in the $\mathrm{CCl}_{4}$ group compared with the control group (Figure 4). Ginseng extract and ginsenoside Rb1 treatments significantly reduced hepatic hydroxyproline level by $36 \%$ and $30 \%$ (Figure $4 \mathrm{~A}$ ) and TIMP-1 level by $27 \%$ and $27 \%$ (Figure $4 \mathrm{C}$ ), respectively, compared with the $\mathrm{CCl}_{4}$ group $(p<0.05)$. However, hepatic MMP-2 level was not different in the three $\mathrm{CCl}_{4}$ treated groups (Figure 4B).

\section{Discussion}

Similar to the previous study [22], plasma ALT and AST activities were increased by $\mathrm{CCl}_{4}$-induced liver injury. Ginseng extract and ginsenoside $\mathrm{Rb} 1$ significantly decreased plasma ALT and AST activities elevated by the exposure to $\mathrm{CCl}_{4}$. The previous studies demonstrated that ginseng extract or heated ginseng exhibited antioxidant activity and acted as a free radical scavenger to inhibit lipid peroxidation in vitro and increase catalase and

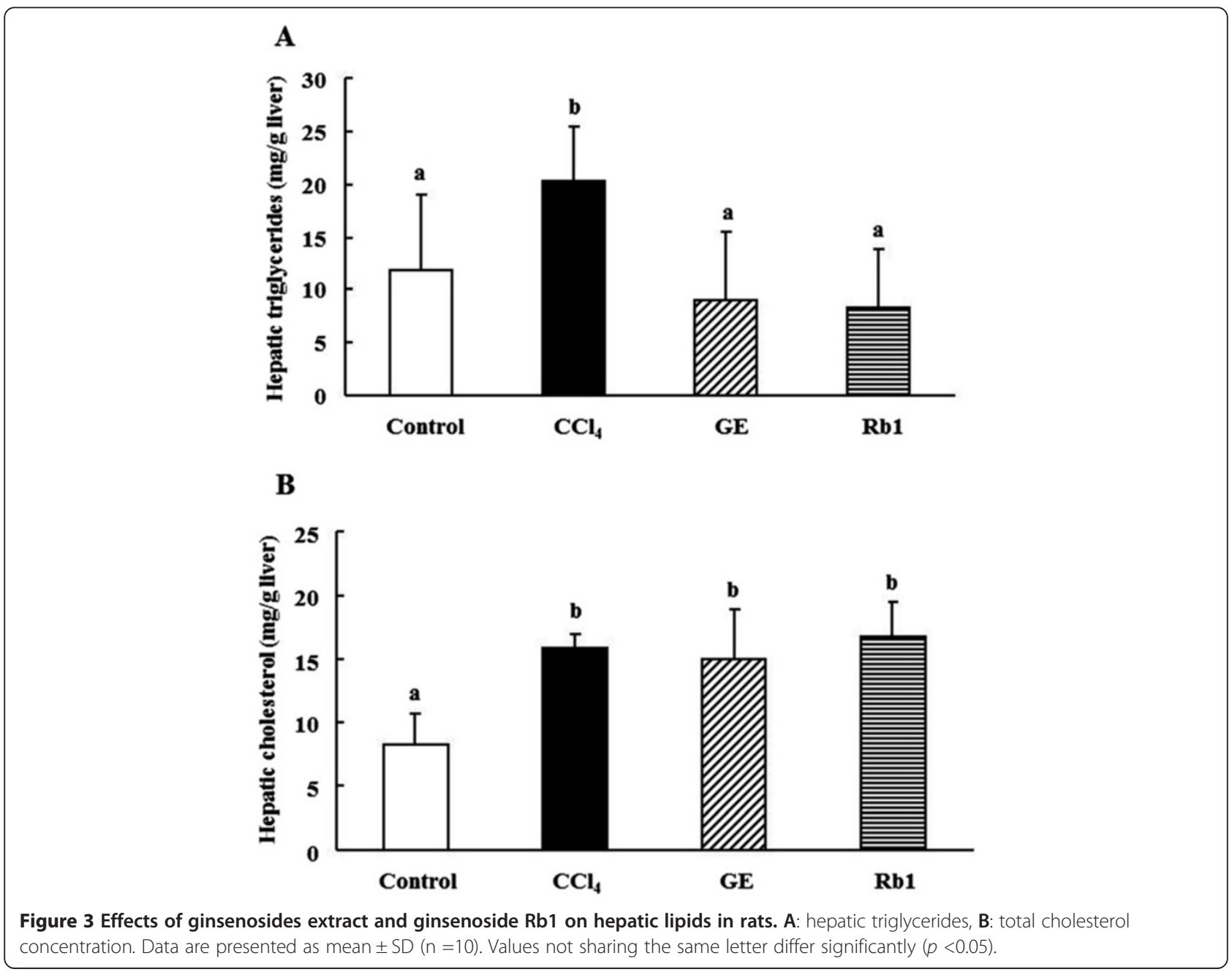


Table 4 Hepatic TNF- $\alpha$, IL-1 $\beta$, IL-10, PGE 2 , and sICAM-1 levels in rats treated with ginsenosides

\begin{tabular}{lllll}
\hline & Control & CCl $_{4}$ & GE & Rb1 \\
\hline TNF-a (pg/mg protein) & $15.8 \pm 7.6^{\mathrm{ab}}$ & $17.2 \pm 5.1^{\mathrm{b}}$ & $10.4 \pm 3.3^{\mathrm{a}}$ & $16.7 \pm 6.9^{\mathrm{b}}$ \\
IL-1 $\beta$ (pg/mg protein) & $132.5 \pm 39.6^{\mathrm{a}}$ & $333.0 \pm 135.8^{\mathrm{c}}$ & $212.0 \pm 115.2^{\mathrm{ab}}$ & $292.9 \pm 182.9^{\mathrm{bc}}$ \\
IL-10 (pg/mg protein) & $4461 \pm 958^{\mathrm{b}}$ & $3443 \pm 508^{\mathrm{a}}$ & $3513 \pm 677^{\mathrm{a}}$ & $3514 \pm 600^{\mathrm{a}}$ \\
PGE 2 (pg/mg protein) & $6196 \pm 1599^{\mathrm{b}}$ & $9822 \pm 2610^{\mathrm{c}}$ & $4636 \pm 1928^{\mathrm{ab}}$ & $4128 \pm 1480^{\mathrm{a}}$ \\
sICAM-1 (pg/mg protein) & $2782 \pm 771^{\mathrm{a}}$ & $3991 \pm 867^{\mathrm{b}}$ & $3288 \pm 567^{\mathrm{ab}}$ & $3427 \pm 963^{\mathrm{ab}}$ \\
\hline
\end{tabular}

Data are presented as mean \pm SD $(n=10)$. Values not sharing the same superscript differ significantly $(p<0.05)$ within the same row.

superoxide dismutase activities in V79-4 lung fibroblast cells $[14,23]$. Moreover, ginsenoside Rb1, Rg1 or derived metabolite-compound $\mathrm{K}$ decreased hepatic malondialdehyde level and increased serum ALT and AST activities $[16,18]$. Therefore, ginseng extract and ginsenoside Rb1, as a free radical scavenger, may eliminate free radical damage to the hepatocytes.

Exposure to $\mathrm{CCl}_{4}$ led to significant increases in the accumulation of fat vacuoles and the levels of triglycerides and total cholesterol in the liver. The abnormal fat accumulation in the liver caused by $\mathrm{CCl}_{4}$ could be attributed to: (1) the imbalance between lipogenesis and lipolysis by increasing lipid synthesis and the rate of lipid esterification [24] as well as by decreasing cAMP production via the stimulation of hormone-sensitive lipase [25,26], and (2) impaired synthesis and secretion of very low density lipoprotein through the interference of glycosylation and maturation of lipoglycoprotein by free radicals which are produced by $\mathrm{CCl}_{4}$ metabolism [24,27], or through the inactivation of $\mathrm{Ca}^{+2}$-ATPase pump in the mitochondria and endoplasmic reticulum $[6,28]$.

Liver damage and elevated hepatic triglycerides induced by $\mathrm{CCl}_{4}$ were improved by the treatment of $\mathrm{GE}$ and $\mathrm{Rb} 1$. Red ginseng saponin, containing ginsenosides $\mathrm{Rb} 1, \mathrm{Rb} 2, \mathrm{Rc}, \mathrm{Rd}, \mathrm{Re}$ and Rg1, played a crucial role in hepatoprotection by suppressing oxidative stress and lipid peroxides via inhibiting the expression and activity of cytochrome P450 in the liver [29]. Consistent with our findings, ginsenoside Rb1 injected intraperitoneally at a dose of $10 \mathrm{mg} / \mathrm{kg}$ body weight for $3 \mathrm{~d}$ significantly decreased hepatic lipids by increasing hepatic cAMP production [30]. Additionally, Rb1 injected intraperitoneally at a dose of $10 \mathrm{mg} / \mathrm{kg}$ body weight also showed to reduce hepatic triglyceride accumulation in high fat dietinduced obese rats by increasing hepatic carnitine palmitoyltransferase 1 activity and cellular AMP/ATP ratio to stimulate fatty acid oxidation and suppress lipogenesis, respectively [31]. Compound $\mathrm{K}$, a major intestinal metabolite of ginsenosides, has been demonstrated to elevate gene expression of peroxisome proliferator-activated receptor- $\alpha$ and decrease gene expression of fatty acid synthase and stearoyl-CoA desaturase 1 through activating AMPactivated protein kinase in HepG2 human hepatoma cells
[32]. The previous study revealed that ginseng extract rich in ginsenosides suppressed hepatic cholesterol synthesis via inhibiting hepatic $\beta$-hydroxy- $\beta$-methylglutaryl-CoA reductase and cholesterol $7 \alpha$-hydroxylase activities [33]. These results suggest that ginseng extract, ginsenoside $\mathrm{Rb} 1$ and their metabolite may accelerate lipid utilization and suppress lipid biosynthesis in the liver to further decrease elevated hepatic triglycerides induced by $\mathrm{CCl}_{4}$ exposure.

Kupffer cells activated by oxidative stress secrete cytokines, such as TNF- $\alpha$ and IL-1 $\beta$, to stimulate the expression of sICAM-1 which induces the activation of neutrophils [7]. The results of $\mathrm{H} \& \mathrm{E}$ staining showed accumulation of inflammatory cells in the $\mathrm{CCl}_{4}$ group. Furthermore, fibrotic bridges were observed in the histopathological sections stained by silver in the $\mathrm{CCl}_{4}$ group as cells became necrotic and reticular fibers resembled after frameworks collapsed. Ginseng extract reduced accumulation of reticular fibers, ameliorated cell necrosis and inhibited production of TNF$\alpha$ and IL-1 $\beta$. In agreement with our present study, in vitro studies demonstrated that ginseng and ginsenoside $\mathrm{Rb} 1$ suppressed TNF- $\alpha$ production and IL- $1 \beta$ mRNA expression in murine RAW264.7 macrophages [34,35]. Ginsenoside Rg1, one of the important components in P. ginseng, intravenously injected at $20 \mathrm{mg} / \mathrm{kg}$ body weight significantly attenuated serum TNF- $\alpha$ and IL- 6 release in septic mice [36].

The expression of $\mathrm{PGE}_{2}$ and cycloogenase-2 (COX-2) are induced by inflammatory response, and the expression of COX-2 was stimulated by proinflammatory cytokines, such as TNF- $\alpha$ and IL-1 $\beta$ [37]. Our present study found that ginseng extract and ginsenoside $\mathrm{Rb} 1$ significantly decreased hepatic $\mathrm{PGE}_{2}$ level induced by $\mathrm{CCl}_{4}$. It is presumed that ginseng extract and ginsenoside $\mathrm{Rb}$ suppressed $\mathrm{PGE}_{2}$ production through reducing proinflammatory cytokines and suppressing COX-2 expression. Furthermore, activation of NF- $\mathrm{KB}$ modulates expression and secretion of proinflammatory cytokines, chemokines, adhesion molecules, COX-2 and inducible nitric oxide synthase (iNOS) [38]. Ginsenoside Rb1, Rg1, Rg3, Rh1 and their derived metabolite compound $\mathrm{K}$ down-regulated activation of NF- $\mathrm{KB}$ and simultaneously suppressed PGE $\mathrm{F}_{2}$ ICAM-1, COX-2 and iNOS expression in vitro $[17,19,39-42]$. It 


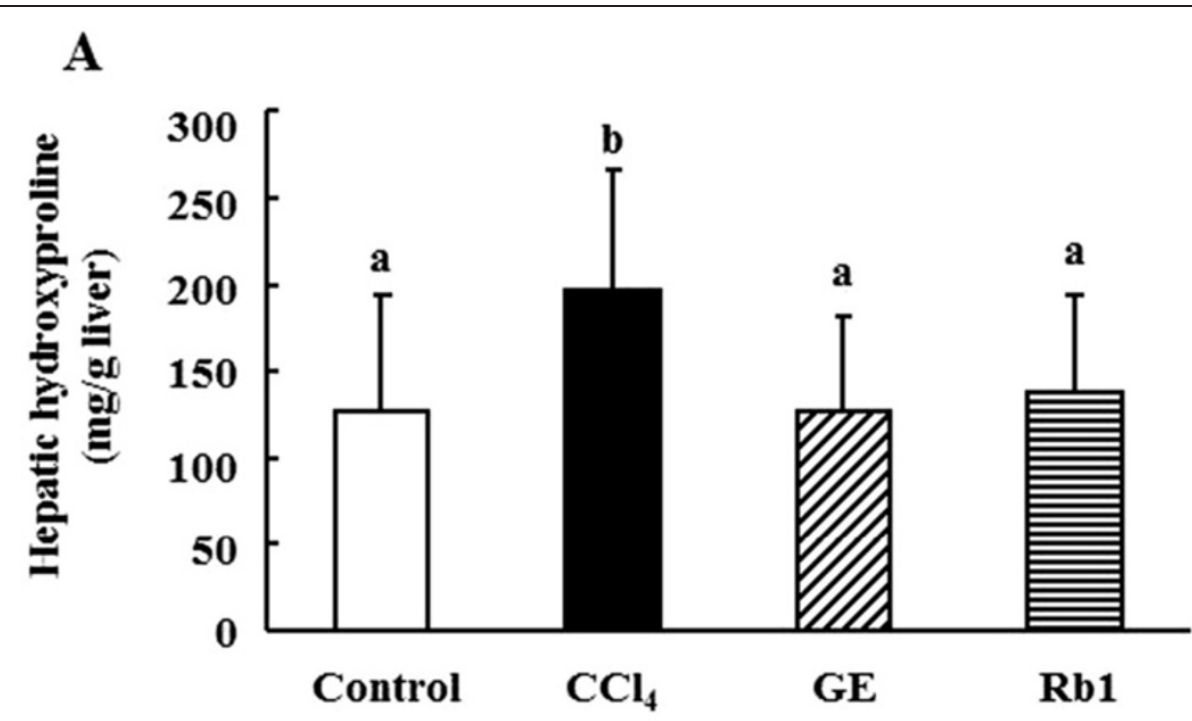

B

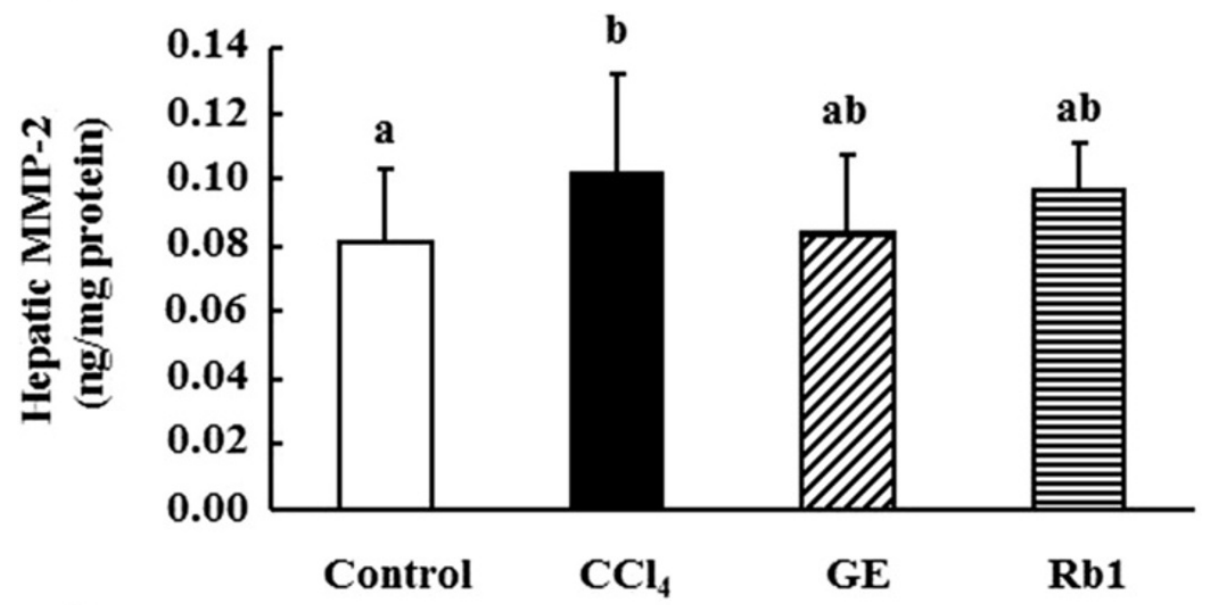

$\mathrm{C}$

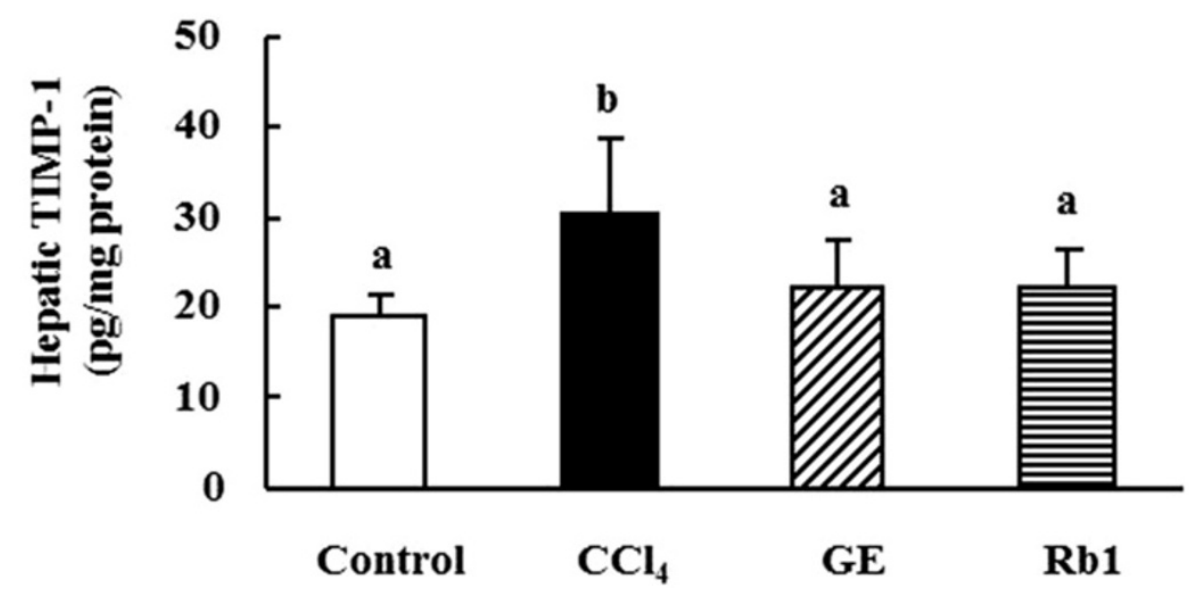

Figure 4 Effects of ginsenosides extract and ginsenoside Rb1 on liver fibrosis markers in rats. A: hepatic hydroxyproline level, B: MMP-2 level; C: TIMP-1 level. Data are presented as mean \pm SD $(n=10)$. Values not sharing the same letter differ significantly $(p<0.05)$. 
is presumed that ginseng extract and ginsenoside Rb1 attenuated production of proinflammatory factors possibly via inhibiting NF- $\mathrm{kB}$ activation.

The accumulation of hydroxyproline and collagen fibers was found in the $\mathrm{CCl}_{4}$ group, whereas ginseng extract and ginsenoside $\mathrm{Rb} 1$ decreased hepatic hydroxyproline and TIMP-1 levels to inhibit liver fibrosis. Oxidative stress induced by $\mathrm{CCl}_{4}$ metabolism could further stimulate proliferation and invasiveness of hepatic stellate cells (HSCs) [43]. Proliferated HSCs resulted in increases in TGF- $\beta 1$ secretion, which activates HSCs and induces gene expression of type I collagen, and induction of collagen accumulation. Activated HSCs express MMPs and their tissue inhibitors (TIMPs). Oxidative stress stimulated MMP-2 production by HSCs via extracellular signal-regulated kinase1/2 and phosphatidylinositol 3 kinase pathways [43], and MMPs induce HSCs proliferation and migration [44]. In vitro studies found that ginsenoside $\mathrm{Rb} 1$ inhibited HSCs activation and mRNA expression of type I and III collagen, TGF- $\beta 1$ and TIMP-1 [45], and its metabolite induced apoptosis in HSCs via caspase- 3 activation pathway [46]. Compound K was found to inhibit MMP-2 expression and NF- $\mathrm{kB}$ activation in the in vitro model [47]. Ginsenoside Rg1 subcutaneously injected at 50 and $100 \mathrm{mg} /$ $\mathrm{kg}$ body weight attenuated serum levels of hyaluronic acid and type III procollagen, and hepatic hydroxyproline level in rats with thioacetamide-induced liver fibrosis [48]. The decrease in activated HSCs could lead to inhibition of fibrogenesis and TIMP-1 expression by reducing TNF- $\alpha$ and TGF- $\beta 1$ [49]. Our finding demonstrated that ginseng extract and ginsenoside Rb1 diminished hepatic TIMP-1 level accompanied with decreased TNF- $\alpha$ level. Therefore, ginseng extract and ginsenoside Rb1 could suppress activation and proliferation of HSCs and further inhibit liver fibrosis.

Ginsenoside Rb1 content was equivalent in the GE and $\mathrm{Rb} 1$ groups in the present study. Ginseng extract with additional seven ginsenosides except for ginsenoside Rb1 more effectively diminished collagen accumulation and inhibited TNF- $\alpha$ production compared with ginsenoside Rb1. Therefore, the hepatoprotective and anti-inflammatory actions of ginseng extract on $\mathrm{CCl}_{4}$ induced liver damage could be attributed to the synergistic action of overall ingredients including the remaining $20 \%$ constituents and their metabolites.

\section{Conclusions}

In conclusion, Panax ginseng extract $(0.5 \mathrm{~g} / \mathrm{kg})$ and ginsenoside Rb1 (0.05 g/kg) decrease plasma ALT and AST activities elevated by $\mathrm{CCl}_{4}$-induced liver damage and inhibit the accumulation of triglycerides in the liver. The levels of TNF- $\alpha, \mathrm{PGE}_{2}$, hydroxyproline and TIMP-1 in the liver are diminished by ginseng extract and ginsenoside Rb1. Therefore, ginseng extract and ginsenoside
$\mathrm{Rb} 1$ attenuate $\mathrm{CCl}_{4}$-induced liver injury through antiinflammatory and antifibrotic effects.

\section{Abbreviations}

ALT: Alanine aminotransferase; AST: Aspartate aminotransferase; $\mathrm{CCl}_{4}$ : Carbon tetrachloride; COX-2: Cycloogenase-2; GE: Ginseng extract; HSCs: Hepatic stellate cells; IL: Interleukin; iNOS: Inducible nitric oxide synthase; MMP: Matrix metalloproteinase; NF-kB: Nuclear factor-kB; NO: Nitric oxide;

$\mathrm{PGE}_{2}$ : Prostaglandin $\mathrm{E}_{2}$; IICAM-1: Soluble intercellular adhesion molecule-1; TGF- $\beta$ : Transforming growth factor- $\beta$; TIMPs: Tissue inhibitor of metalloproteinases; TNF-a: Tumor necrosis factor-a.

\section{Competing interests}

The authors declare that they have no competing interest.

\section{Authors' contributions}

JCC designed the research. YLH and YHL performed the research. YLH, YHT, YHL and JCC analyzed the data. YLH, YHT and JCC wrote the paper. All authors have read and approved the final manuscript.

\section{Acknowledgements}

This study was supported by the Ministry of Science and Technology, Republic of China (grant NSC95-2320-B-038-038-MY2).

\section{Author details}

${ }^{1}$ School of Nutrition and Health Sciences, College of Public Health and Nutrition, Taipei Medical University, Taipei 110, Taiwan. ${ }^{2}$ School of Dentistry, Taipei Medical University, Taipei 110, Taiwan. ${ }^{3}$ Master Program in Global Health and Development, College of Public Health and Nutrition, Taipei Medical University, Taipei 110, Taiwan. ${ }^{4}$ Nutrition Research Center, Taipei Medical University Hospital, Taipei 110, Taiwan.

Received: 29 July 2014 Accepted: 16 October 2014

Published: 25 October 2014

\section{References}

1. Neubauer K, Saile B, Ramadori G: Liver fibrosis and altered matrix synthesis. Can J Gastroenterol 2001, 15(3):187-193.

2. Kew MC, Popper H: Relationship between hepatocellular carcinoma and cirrhosis. Semin Liver Dis 1984, 4(2):136-146.

3. Lu SN, Su WW, Yang SS, Chang TT, Cheng KS, Wu JC, Lin HH, Wu SS, Lee CM, Changchien CS, Chen CJ, Sheu JC, Chen DS, Chen CH: Secular trends and geographic variations of hepatitis $B$ virus and hepatitis $C$ virusassociated hepatocellular carcinoma in Taiwan. Int J Cancer 2006, 119 (8):1946-1952.

4. Siegmund SV, Brenner DA: Molecular pathogenesis of alcohol-induced hepatic fibrosis. Alcohol Clin Exp Res 2005, 29(11 Suppl):102S-109S.

5. Luster MI, Simeonova PP, Gallucci RM, Matheson JM, Yucesoy B: Immunotoxicology: role of inflammation in chemical-induced hepatotoxicity. Int J Immunopharmacol 2000, 22(12):1143-1147.

6. Weber LW, Boll M, Stampfl A: Hepatotoxicity and mechanism of action of haloalkanes: carbon tetrachloride as a toxicological model. Crit Rev Toxicol 2003, 33(2):105-136.

7. Ramadori G, Armbrust T: Cytokines in the liver. Eur J Gastroenterol Hepatol 2001, 13(7):777-784.

8. Simeonova PP, Gallucci RM, Hulderman T, Wilson R, Kommineni C, Rao M, Luster Ml: The role of tumor necrosis factor-a in liver toxicity, inflammation, and fibrosis induced by carbon tetrachloride. Toxicol Appl Pharmacol 2001, 177(2):112-120.

9. Knittel T, Mehde M, Grundmann A, Saile B, Scharf JG, Ramadori G: Expression of matrix metalloproteinases and their inhibitors during hepatic tissue repair in the rat. Histochem Cell Biol 2000, 113(6):443-453.

10. Lim W, Mudge KW, Vermeylen F: Effects of population, age, and cultivation methods on ginsenoside content of wild American ginseng (Panax quinquefolium). J Agric Food Chem 2005, 53(22):8498-8505.

11. Kim MW, Ko SR, Choi KJ, Kim SC: Distribution of saponin in various sections of Panax ginseng root and changes of its contents according to root age. Korean J Ginseng Sci 1987, 11(1):10-16.

12. Cicero AF, Vitale G, Savino G, Arletti R: Panax notoginseng (Burk.) effects on fibrinogen and lipid plasma level in rats fed on a high-fat diet. Phytother Res 2003, 17(2):174-178. 
13. Yu JL, Duo DQ, Chen XH, Yang HZ, Guo N, Cheng GF: Protopanaxatrioltype ginsenosides differentially modulated type 1 and type 2 cytokines production from murine splenocytes. Planta Med 2005, 71(3):202-207.

14. Kitts DD, Wijewickreme AN, Hu C: Antioxidant properties of a North American ginseng extract. Mol Cell Biochem 2000, 203(1-2):1-10.

15. Lee SH, Seo GS, Ko G, Kim JB, Sohn DH: Anti-inflammatory activity of 20 (S)-protopanaxadiol: enhanced heme oxygenase 1 expression in RAW 264.7 cells. Planta Med 2005, 71(12):1167-1170.

16. Deng HL, Zhang JT: Anti-lipid peroxidative effect of ginsenoside Rb1 and Rg1. Chin Med J 1991, 104(5):395-398.

17. Wang J, Qiao L, Li Y, Yang G: Ginsenoside Rb1 attenuates intestinal ischemia-reperfusion-induced liver injury by inhibiting NF-KB activation. Exp Mol Med 2008, 40(6):686-698.

18. Lee HU, Bae EA, Han MJ, Kim NJ, Kim DH: Hepatoprotective effect of ginsenoside $\mathrm{Rb} 1$ and compound $\mathrm{K}$ on tert-butyl hydroperoxide-induced liver injury. Liver Int 2005, 25(5):1069-1073.

19. Park EK, Shin YW, Lee HU, Kim SS, Lee YC, Lee BY, Kim DH: Inhibitory effect of ginsenoside $\mathrm{Rb} 1$ and compound $\mathrm{K}$ on $\mathrm{NO}$ and prostaglandin $\mathrm{E} 2$ biosyntheses of RAW264.7 cells induced by lipopolysaccharide. Biol Pharm Bull 2005, 28(4):652-656.

20. Das S, Santra A, Lahiri S, Guha Mazumder DN: Implication of oxidative stress and hepatic cytokine (TNF-a and IL-6) response in the pathogenesis of hepatic collagenesis in chronic arsenic toxicity. Toxicol Appl Pharmacol 2005, 204(1):18-26

21. Lowry OH, Rosebrough NJ, Farr AL, Randall RJ: Protein measurement with the Folin phenol reagent. J Biol Chem 1951, 193(1):265-275.

22. Lee TY, Mai LM, Wang GJ, Chiu JH, Lin YL, Lin HC: Protective mechanism of salvia miltiorrhiza on carbon tetrachloride-induced acute hepatotoxicity in rats. J Pharmacol Sci 2003, 91(3):202-210.

23. Kim KT, Yoo KM, Lee JW, Eom SH, Hwang IK, Lee CY: Protective effect of steamed American ginseng (Panax quinquefolius L.) on V79-4 cells induced by oxidative stress. J Ethnopharmacol 2007, 111(3):443-450.

24. Boll M, Weber LW, Becker E, Stampfl A: Pathogenesis of carbon tetrachloride-induced hepatocyte injury bioactivation of $\mathrm{CCl}_{4}$ by cytochrome P450 and effects on lipid homeostasis. Z Naturforsch C 2001, 56(1-2):111-121.

25. Zhu SL, Chen L, Gao W, Zhou J: Changes of some immune-mediators in $\mathrm{CCl}_{4}$-induced liver injury mice. Shi Yan Sheng Wu Xue Bao 2004, 37(1):50-54

26. Carmen GY, Victor SM: Signalling mechanisms regulating lipolysis. Cell Signal 2006, 18(4):401-408.

27. Barisione G, Fontana L, Cottalasso D, Domenicotti C, Pronzato MA, Nanni G: Changes in lipoglycoprotein metabolism in toxic fatty liver. Minerva Gastroenterol Dietol 1993, 39(3):101-112.

28. Björnsson OG, Bourgeois CS, Gibbons GF: Varying very low-density lipoprotein secretion of rat hepatocytes by altering cellular levels of calcium and the activity of protein kinase C. Eur J Clin Invest 1998, 28(9):720-729.

29. Kim HJ, Chun YJ, Park JD, Kim SI, Roh JK, Jeong TC: Protection of rat liver microsomes against carbon tetrachloride-induced lipid peroxidation by red ginseng saponin through cytochrome P450 inhibition. Planta Med 1997, 63(5):415-418.

30. Park JH, Shin HJ, Song YB, Hyun HC, Cho HJ, Ham HS, Yoo YB, Ko YC, Jun WT, Park $\mathrm{HJ}$ : Possible role of ginsenoside $\mathrm{Rb} 1$ on regulation of rat liver triglycerides. Biol Pharm Bull 2002, 25(4):457-460.

31. Shen L, Xiong Y, Wang DQ, Howles P, Basford JE, Wang J, Xiong YQ, Hui DY, Woods SC, Liu M: Ginsenoside Rb1 reduces fatty liver by activating AMPactivated protein kinase in obese rats. J Lipid Res 2013, 54(5):1430-1438.

32. Kim DY, Yuan HD, Chung IK, Chung SH: Compound K, intestinal metabolite of ginsenoside, attenuates hepatic lipid accumulation via AMPK activation in human hepatoma cells. J Agric Food Chem 2009, 57(4):1532-1537

33. Qureshi AA, Abuirmeileh N, Din ZZ, Ahmad Y, Burger WC, Elson CE: Suppression of cholesterogenesis and reduction of LDL cholesterol by dietary ginseng and its fractions in chicken liver. Atherosclerosis 1983, 48(1):81-94

34. Cho JY, Yoo ES, Baik KU, Park MH, Han BN: In vitro inhibitory effect of protopanaxadiol ginsenosides on tumor necrosis factor (TNF)- $a$ production and its modulation by known TNF-a antagonists. Planta Med 2001, 67(3):213-218
35. Rhule A, Navarro S, Smith JR, Shepherd DM: Panax notoginseng attenuates LPS-induced pro-inflammatory mediators in RAW264.7 cells. J Ethnopharmacol 2006, 106(1):121-128.

36. Zou Y, Tao T, Tian Y, Zhu J, Cao L, Deng X, Li J: Ginsenoside Rg1 improves survival in a murine model of polymicrobial sepsis by suppressing the inflammatory response and apoptosis of lymphocytes. J Surg Res 2013, 183(2):760-766.

37. Crofford LJ: COX-1 and COX-2 tissue expression: implications and predictions. J Rheumato/ Supp/ 1997, 49:15-19.

38. Hanada T, Yoshimura A: Regulation of cytokine signaling and inflammation. Cytokine Growth Factor Rev 2002, 13(4-5):413-421.

39. Wang N, Wan JB, Chan SW, Deng YH, Yu N, Zhang QW, Wang YT, Lee SM: Comparative study on saponin fractions from Panax notoginseng inhibiting inflammation-induced endothelial adhesion molecule expression and monocyte adhesion. Chin Med 2011, 6:37. doi: 10.1186/1749-8546-6-37.

40. Lee ES, Choi JS, Kim MS, You HJ, Ji GE, Kang YH: Ginsenoside metabolite compound $\mathrm{K}$ differentially antagonizing tumor necrosis factor-a-induced monocyte-endothelial trafficking. Chem Biol Interact 2011, 194(1):13-22.

41. Hien TT, Kim ND, Kim HS, Kang KW: Ginsenoside Rg3 inhibits tumor necrosis factor-alpha-induced expression of cell adhesion molecules in human endothelial cells. Pharmazie 2010, 65(9):699-701.

42. Oh GS, Pae HO, Choi BM, Seo EA, Kim DH, Shin MK, Kim JD, Kim JB, Chung HT: 20(S)-Protopanaxatriol, one of ginsenoside metabolites, inhibits inducible nitric oxide synthase and cyclooxygenase- 2 expressions through inactivation of nuclear factor-kB in RAW 264.7 macrophages stimulated with lipopolysaccharide. Cancer Lett 2004, 205(1):23-29.

43. Galli A, Svegliati-Baroni G, Ceni E, Milani S, Ridolfi F, Salzano R, Tarocchi M, Grappone C, Pellegrini G, Benedetti A, Surrenti C, Casini A: Oxidative stress stimulates proliferation and invasiveness of hepatic stellate cells via a MMP2-mediated mechanism. Hepatology 2005, 41(5):1074-1084.

44. Benyon RC, Hovell CJ, Da Gaça M, Jones EH, Iredale JP, Arthur MJ: Progelatinase $\mathrm{A}$ is produced and activated by rat hepatic stellate cells and promotes their proliferation. Hepatology 1999, 30(4):977-986.

45. Lo YT, Tsai YH, Wu SJ, Chen JR, Chao JC: Ginsenoside Rb1 inhibits cell activation and liver fibrosis in rat hepatic stellate cells. J Med Food 2011, 14(10):1135-1143.

46. Park EJ, Zhao YZ, Kim J, Sohn DH: A ginsenoside metabolite, 20-O- $\beta-D-$ glucopyranosyl-20(S)-protopanaxadiol, triggers apoptosis in activated rat hepatic stellate cells via caspase-3 activation. Planta Med 2006, 72(13):1250-1253.

47. Ming Y, Chen Z, Chen L, Lin D, Tong Q, Zheng Z, Song G: Ginsenoside compound $\mathrm{K}$ attenuates metastatic growth of hepatocellular carcinoma, which is associated with the translocation of nuclear factor-KB p65 and reduction of matrix metalloproteinase-2/9. Planta Med 2011, 77(5):428-433.

48. Geng J, Peng W, Huang Y, Fan H, Li S: Ginsenoside-Rg1 from Panax notoginseng prevents hepatic fibrosis induced by thioacetamide in rats. Eur J Pharmacol 2010, 634(1-3):162-169.

49. Knittel T, Mehde M, Kobold D, Saile B, Dinter C, Ramadori G: Expression patterns of matrix metalloproteinases and their inhibitors in parenchymal and non-parenchymal cells of rat liver: regulation by TNF-a and TGF- $\beta 1$. J Hepatol 1999, 30(1):48-60.

doi:10.1186/1472-6882-14-415

Cite this article as: Hou et al:: Ginseng extract and ginsenoside $\mathrm{Rb} 1$ attenuate carbon tetrachloride-induced liver fibrosis in rats. BMC Complementary and Alternative Medicine 2014 14:415. 